\title{
Forming impressions of personality: The effect of the initial impression ${ }^{1}$
}

\author{
MARTIN F. KAPLAN, Northern Illinois \\ University, DeKalb, Ill. 60115
}

Personality differences in impression formation were investigated as a function of initial impression, or response dispositions. Ss emitting positive or negative traits in describing a generalized "other" (PI and NI Ss, respectively) rated likeability of persons described by sets of favorable $(H)$ or unfavorable $(L)$ traits of varying set size. As predicted by a model of information integration in which an impression is a weighted average of trait components and an initial impression, PI rated both $H$ and $L$ trait sets more positively than did NI. The prediction that personality differences would diminish with increased set size was not supported. It was suggested that redundancy is an important factor in determining the effect of increased information on personality differences in impression formation.

The process of forming an impression of another may be conceptualized as involving the integration of separate items of information into a unitary judgment. Several formulations of this integration process have been proposed, alternately suggesting a summation of the separate components (Fishbein \& Hunter, 1964), an averaging of the components, with separate weights related to the extremity of each element (Manis, Gleason, \& Dawes, 1966; Osgood \& Tannenbaum, 1955), and a weighted average of the components and an initial impression (Anderson, 1967). While personality effects in impression formation may be mediated by a variety of variables, the present study is concerned with the effect of systematic evaluative predispositions on the impression. Although it might be expected that consistent dispositional effects occur in social perception (Kaplan, 1968a; Shrauger \& Altrocchi, 1964), Anderson's formulation is the only one to include a judge's evaluative predisposition in its formal statement of the integration model. For this reason, as well as the fact that it has received a large body of experimental support (cf. Anderson, 1968b), the present study tests several implications for preexisting dispositional differences following from this model.

According to the weighted average model (Anderson, 1967), the person impression is a weighted average of two sets of components: information and judge's initial impression, such that

$$
\mathbf{R}_{k}=\frac{k w A}{k w+(1-w)}+\frac{(1-w) I o}{k w+(1-w)}
$$

where $R_{k}$ is the person impression, $k$ is the size of the set of information, $A$ is the scale value of a single stimulus, Io is the initial or a priori impression, and $w$, the weight associated with the information (Anderson, 1967). The term on the left thus denotes informational effects on judgments and the right denotes the impression based on a lack of information (Anderson, 1968b, p. 737). Thus, Io may be considered an allowance for judge dispositions or preexisting impression biases. In a goodness-of-fit test of the model (Anderson, 1967), Io was assumed to be neutral, for the sake of simplicity in calculation. While it seems reasonable to assume that, on the average, people's response dispositions or Io are neutral, it seems equally reasonable to expect that individual differences exist. Such differences would be expected to manifest themselves through differences in the value of the lo term. To the extent that $k$, the amount of information, is increased, the importance of the dispositional term approaches zero.

For purposes of assessing response dispositions, it is assumed that they are related to response availability. Thus, preexisting Io can be inferred from responses a person has readily available for judging others and their relative strength. Garskof, Shapiro, \& Brandstadter (1967) found order of emission of responses in continued association to be a valid index of response strength in word association, and Kaplan (1966), eliciting general attributes of Negroes from judges in continued association, found estimates based on the first nine emitted were accurate predictors of attitude. Accordingly, Io may be inferred from the salient response tendencies elicited in continued association to a generalized social stimulus. Support for this assumption may be obtained from a study in which judges with predominantly affiliative responses in the response hierarchy obtained by continued association tended to make more sociability judgments for a contrived stimulus person than did judges lacking these responses (Kaplan, 1968a).
It would be predicted, following a weighted average model, that preexisting differences in initial impression would be associated with differences in person impression. Further, it would be predicted that such differences in person impressions would be constant across stimulus values, i.e., the Information Polarity by Initial Impression interaction should be zero. Finally, since the effect of initial inpression is predicted to decrease as the effect of informational variables increases, the magnitude of group differences in person impressions should be inversely related to set size, or amount of information in the stimulus complex.

\section{SUBJECTS}

Six hundred male students in an introductory psychology class -were asked to list, in continued association for $7 \mathrm{~min}$, words that could describe other people's behavior. For each resultant response hierarchy, each of the first 12 words emitted was scored for positive, negative, or neutral valence by four judges. A more detailed description of this procedure and scoring criteria may be found elsewhere (Kaplan, 1968a, b). Ss with five or more positive and one or less negative words were designated as possessing positive initial impressions (PI), and the opposite pattern identified negative initial impressions (NI). Eighteen Ss were selected from each group for further participation in the experiment.

\section{PROCEDURE}

The procedure was essentially a replication of Anderson's (1967) study, with the addition of the between-Ss factor of initial impression. $S$ received a set of adjectives and was told each adjective was supplied by a different acquaintance of the stimulus person. $S$ was asked to rate the person described by each set on a rating scale of -35 to +35 , with -35 anchored at "Dislike very much" and +35 at "Like very much." Scores were then converted to a 0-70 scale to simplify analysis.

Experimental sets were constructed by combining either highly favorable $(\mathrm{H})$ or highly unfavorable (L) adjectives into sets of one, two, three, four, or six stimul: The specific adjectives used were identical to those reported by Anderson (1967), favorability being determined by mean rating in a normative sample (Anderson, 1968a). Thus, there were two main subgroups of trait sets corresponding to favorability, with six replications of Set Size 1 within each subgroup, three of Set Size 2, two of Set Size 3, three of Set Size 4, and one of Set Size 6. This procedure was repeated for a second series of six $\mathrm{H}$ and six $\mathrm{L}$ adjectives, yielding a total of 60 sets. In addition, 14 moderately 
favorable and 14 moderately unfavorable filler sets of varying set size were included, as well as 12 practice sets of mixed favorability and set size. Each set was typed on a card for simultaneous presentation, vertical order of adjectives being determined randomly, and experimental and filler sets were ordered randomly for each $S$.

\section{RESULTS}

Mean ratings are found in Table 1 . Sets with $\mathrm{H}$ traits were rated more positively than were those with $\mathrm{L}$ traits, and a marked set size effect was noted. That is, $\mathrm{H}$ sets were rated more favorably, and $L$ sets were rated more unfavorably, with increasing set size. This observation is supported by a significant Favorability by Set Size interaction in ANOVA $(F=27.5$, df $=4 / 136, p<.01)$.

The major hypothesis dealt with the effect of initial impression differences on ratings, and these were found to be significant. PI Ss generally rated the stimulus sets more positively than did NI Ss, as predicted $(F=4.4, \quad \mathrm{df}=1 / 34$, $\mathrm{p}<.05$ ).

It was further predicted from the averaging model that rating differences due to initial impression would diminish with increased set size. Comparison of the columns in Table 1 suggest, however, that this was not the case. Support for this observation is provided by the obtained initial impression by set-size $F$ ratio, which was insignificant $(F=.22, \mathrm{df}=4 / 136)$.

The weighted average model requires that the difference cue to initial impression be consistent across $\mathrm{H}$ and $\mathrm{L}$ sets. Although

Table 1

Mean Person Impressions as a Function of Trait Favorability, Initial Impression, and Set Size

\begin{tabular}{|c|c|c|c|c|}
\hline \multirow{2}{*}{$\begin{array}{l}\text { Set } \\
\text { Size }\end{array}$} & \multicolumn{2}{|c|}{$\begin{array}{c}\text { Favorable } \\
\text { Traits }\end{array}$} & \multicolumn{2}{|c|}{$\begin{array}{c}\text { Unfavorable } \\
\text { Traits }\end{array}$} \\
\hline & PI & $\mathrm{Nl}$ & PI & $\mathrm{NI}$ \\
\hline 1 & 58.61 & 53.95 & 18.14 & 16.39 \\
\hline 2 & 61.16 & 56.20 & 12.91 & 12.58 \\
\hline 3 & 62.60 & 59.40 & 11.62 & 10.06 \\
\hline 4 & 64.61 & 60.52 & 7.85 & 7.31 \\
\hline 6 & 66.72 & 62.42 & 7.17 & 6.33 \\
\hline
\end{tabular}

the expected differences may be observed to be smaller for the $L$ sets, the interaction between initial impression and trait favorability was negligible $(F=1.7$, $\mathrm{df}=1 / 34$ ), conforming to the model. Effects of initial impression, or response dispositions, therefore, while present in impression ratings, are not specific to the valence of the stimuli, nor are they contingent on the amount of information available, at least within the limits investigated in the present study.

\section{DISCUSSION}

Group differences in impression formation were predictable from estimates of judge's initial impression based on the relative strength of the responses available for judging behavior of others. This finding furnishes indirect support for Anderson's weighted average model, as the model allows for effects due to initial impression. Further support derives from the fact that this effect was linear, that is, noninteractive with stimulus polarity.

The prediction of diminishing response differences between $S$ groups with increased set size was not confirmed. The fact that the Io groups maintained their differences in person impressions across set sizes is contrary to a model in which the contribution of the dispositional factor is dependent, in part, on amount of information. While this may represent a departure from the model, it is also possible that increments in set size were not, in the present study, associated with equal increments in information due to redundancy. Since stimuli within sets were homogeneous in valence, it is conceivable that the extent to which any one trait implied another increased with set size. Replication, controlling for redundancy, seems advisable.

Since lo is a dispositional factor, it may be considered as one instance of the effect of personality factors on impression formation. This does not imply that personality factors influence impressions only through Io. For example, observed personality effects in the integration process, e.g., the role of cognitive complexity in reconciling inconsistencies (Mayo \& Crockett, 1964), may affect response by influencing component weights.

\section{REFERENCES}

ANDERSON, N. H. Averaging model analysis of set-size effect in impression formation. Journal of Experimental Psychology, 1967, 75, 158-165.

ANDERSON, N. H. Likableness ratings of 555 personality trait words. Journal of Personality \& Social Psychology, 1968a, 9, 272-279.

ANDERSON, N. H. A simple model for information integration. In R. P. Abelson, E. Aronson, W. J. McGuire, T, M. Newcomb, M. J. Rosenberg, and P. H. Tannenbaum (Eds.), Theories of cognitive consistency: $A$ source book. Chicago: Rand McNally, $1968 \mathrm{~b}$. Pp. 731-743.

FISHBEIN, M., \& HUNTER, R. Summation vs balance in attitude organization and change. Journal of Abnormal \& Social Psychology, $1964,69,505-510$.

GARSKOF, B. E., SHAPIRO, E. G, \& BRANDSTADTER, $J$. Order of emission in continual association as a predictor of individual free recall. Psychonomic Science, 1967, 7, 209.210.

KAPLAN, K. J. A methodological comparison of two techniques of attitude measurement. Unpublished Master's thesis, University of Illinois, 1966.

KAPLAN, M. F. Behavior prediction responses as a function of judge's response hierarchy. Paper presented at meetings of the Midwestern Psychological Association, Chicago, 1968a.

KAPLAN, M. F. Differentiation among targets in social perception as a function of response hierarchy. Psychonomic Science, 1968b, 10 . 227-228.

MAYO, C. W., \& CROCKETT, W. H. Cognitive complexity and primacy-recency effects in impression formation. Journal of Abnormal \& Socjal Psychology, 1964, 68, 335-338.

MANIS, M., GLEASON, T. C., \& DAWIS, R. M. Evaluation of complex social stimuli. Journal of Personality \& Social Psychology, 1966, 3 , 404-419.

OSGOOD, C. E.. \& TANNENBAUM, P. H. The principle of congruity in the prediction of attitude change. Psychological Review, 1955, 62, 42-55.

SHRAUGER, S., \& ALTROCCHI, J. The personality of the perceiver as a factor in person perception. Psychological Bulletin, $1964,62,289-308$

\section{NOTE}

1. Appreciation is extended to Ed Donnerstein for assistance in collecting data and to Norman Anderson for critical comments on a draft of this paper. 